\title{
Correction to: The role of renewables in the Japanese power sector: implications from the EMF35 JMIP
}

\author{
Hiroto Shiraki ${ }^{1}$ (D) Masahiro Sugiyama ${ }^{2}$ (]) Yuhji Matsuo $^{3} \cdot$ Ryoichi Komiyama $^{4} \cdot$ Shinichiro Fujimori $^{5,6,7}$. \\ Etsushi Kato ${ }^{8} \cdot$ Ken Oshiro $^{5} \cdot$ Diego Herran Silva ${ }^{6,9}$
}

Published online: 6 March 2021

(c) The Author(s) 2021

\section{Correction to: Sustainability Science https://doi.org/10.1007/s11625-021-00917-y}

In the original publication of the article, the incorrect file was published as supplementary material.

The supplementary file "Supplementary file1" has been replaced.

The original article has been updated.

Supplementary Information The online version contains supplementary material available at https://doi.org/10.1007/s11625-021-00934-x.

Open Access This article is licensed under a Creative Commons Attribution 4.0 International License, which permits use, sharing, adaptation, distribution and reproduction in any medium or format, as long

The original article can be found online at https://doi.org/10.1007/ s11625-021-00917-y.

Hiroto Shiraki

shiraki.h@ses.usp.ac.jp

1 School of Environmental Science, The University of Shiga Prefecture, 2500 Hassaka, Hikone, Shiga 522-8533, Japan

2 Institute for Future Initiatives, The University of Tokyo, Tokyo, Japan

3 Institute of Energy Economics, Tokyo, Japan

4 School of Engineering, The University of Tokyo, Tokyo, Japan

5 Department of Environmental Engineering, Kyoto University, Kyoto, Japan

6 National Institute for Environmental Studies, 16-2 Onogawa, 305-8506 Tsukuba, Ibaraki, Japan

7 International Institute for Applied Systems Analysis, Laxenburg, Austria

8 Institute of Applied Energy, Minato, Tokyo, Japan

9 Institute for Global Environmental Strategies, 2108-11 Kamiyamaguchi, 240-0115 Kanagawa, Hayama, Japan as you give appropriate credit to the original author(s) and the source, provide a link to the Creative Commons licence, and indicate if changes were made. The images or other third party material in this article are included in the article's Creative Commons licence, unless indicated otherwise in a credit line to the material. If material is not included in the article's Creative Commons licence and your intended use is not permitted by statutory regulation or exceeds the permitted use, you will need to obtain permission directly from the copyright holder. To view a copy of this licence, visit http://creativecommons.org/licenses/by/4.0/.

Publisher's Note Springer Nature remains neutral with regard to jurisdictional claims in published maps and institutional affiliations. 